\title{
Neonatal Nonketotic Hyperglycinemia: A Rare Case from Pakistan
}

\author{
Taha Bin Arif $^{1}$, Jawad Ahmed ${ }^{1}$, Farheen Malik ${ }^{1}$, Sharmeen Nasir ${ }^{2}$, Taj M. Khan ${ }^{3}$ \\ 1. Internal Medicine, Dow University of Health Sciences, Karachi, PAK 2. Pediatrics, Dow University of Health Sciences, \\ Karachi, PAK 3. Pediatrics, Baylor College of Medicine/Texas Children's Hospital, Houston, USA
}

Corresponding author: Jawad Ahmed, jawadahmedd13@gmail.com

\begin{abstract}
Nonketotic hyperglycinemia (NKH) is an autosomal recessive disorder caused by a defect in glycine cleavage enzyme. It leads to the accumulation of glycine in the body tissues, blood, and cerebrospinal fluid (CSF). Most NKH cases are diagnosed during the natal period of life and are fatal if not promptly diagnosed and managed. Here we present a case of a two-day-old child who presented with reluctant feeding and lethargy. She had reduced tone in all four limbs and a Glasgow Coma Scale score of 9. Keeping an infectious etiology in mind, she was started on cefotaxime and amikacin. The patient was shifted to the neonatal intensive care unit; however, no improvement in the patient's condition was seen and antibiotics were changed to linezolid and meropenem along with initiation of acyclovir. The patient's blood and CSF cultures were negative. Serum amino acid chromatography showed elevated levels of glycine, and a diagnosis of NKH was made. The patient was managed symptomatically but expired on the 22nd day of admission. The case highlights the importance of prompt diagnosis and management of aminoacidopathies. Nearly all metabolic disorders have similar clinical presentations, and an early diagnosis can improve the outcome in patients.
\end{abstract}

Categories: Endocrinology/Diabetes/Metabolism, Emergency Medicine, Pediatrics

Keywords: nonketotic hyperglycinemia, glycine cleavage enzyme, autosomal recessive disorder, glycine cleavage system, glycine encephalopathies, neonates, lethargy, poor feeding

\section{Introduction}

Nonketotic hyperglycinemia (NKH) is an autosomal recessive (AR) disorder, in which glycine metabolism of the body is impaired consequently causing a disproportionate increase and accumulation of glycine in all body tissues, including the central nervous system (CNS) [1]. The primary defect lies in the liver enzyme complex, called the glycine cleavage system. NKH is a rare disease with an estimated incidence of 1 per 250,000 [2]. Glycine encephalopathy has been broadly classified into four major forms; neonatal, infantile, transient, and late. Most glycine encephalopathies occur in the neonates. The disease usually manifests itself within the first few days of life with hypotonia, lethargy, seizures, myoclonic jerks, hiccups, and apnea, which if left untreated can lead to death [3]. In some cases, congenital brain anomalies like hypoplastic corpus callosum and retrocerebellar cyst with hydrocephalus have been reported in association $[4,5]$. NKH has a very poor prognosis, with a high mortality rate of up to $50 \%$ during the first week of life [6]. Therefore,

Received 03/04/2020

Review began 03/09/2020 Review ended 03/09/2020 Published 03/10/2020

\section{○) Copyright 2020}

Bin Arif et al. This is an open access article distributed under the terms of the Creative Commons Attribution License CC-BY 4.0., which permits unrestricted use, distribution, and reproduction in any medium, provided the original author and source are credited. we felt it is imperative to report this case, with the intention to broaden the differential of clinicians when a child presents with hypotonia, encephalopathy, and seizures. Here we present a case of a two-day-old female who was brought to the pediatrics emergency department (PED) with a history of reluctant feeding and lethargy.

\section{Case Presentation}

A two-day-old female neonate, unvaccinated, was brought to PED of Civil Hospital Karachi, with complaints of reluctance to feed and lethargy for one day. She was neither taking breastfeed nor formula milk. There was no history of fever, fits, vomiting, or diarrhea. She was the third product of consanguineous marriage and was born via elective cesarean (C-section) at 34 weeks of gestation. The elder two siblings were healthy and alive. No significant family history of miscarriage or stillbirth, chronic disease, or expiry at an early age. Birth history was unremarkable.

On examination, she looked severely lethargic and had a weak cry. She was afebrile with a heart rate of 125 beats/min, respiratory rate of 30 breaths/min, oxygen saturation of $98 \%$, and random blood sugar (RBS) of $80 \mathrm{mg} / \mathrm{dL}$. Anthropometric measurements showed fronto-occipital circumference of $31 \mathrm{~cm}$, length of $42 \mathrm{~cm}$, and weight of $2.1 \mathrm{~kg}$. There were no signs of anemia, jaundice, cyanosis, dehydration, or edema. CNS examination revealed a lethargic child with low Glasgow Coma Scale (GCS) score of 9 with decreased tone in all four limbs, and flat and open anterior fontanelle. Moro, rooting, sucking, and grasping reflexes were poor. The rest of the examinations were unremarkable.

Differential diagnosis of late-preterm with sepsis, meningitis, or encephalitis was established. The patient was initially kept nil per oral and oxygen was provided. She was managed on intravenous (IV) $160 \mathrm{~mL} 10 \%$ dextrose water over 24 hours, IV $160 \mathrm{mg}$ cefotaxime BD, and IV $16 \mathrm{mg}$ amikacin BD. On day 1 , the patient 
developed apnea along with bradycardia and RBS showed a minute increase to $84 \mathrm{mg} / \mathrm{dL}$. She was resuscitated and revived. Aminophylline $12 \mathrm{mg}$ IV stat was given. The patient was shifted to neonatal intensive care unit (NICU), intubated, and put on a ventilator.

The initial investigations (at day of admission) revealed a hemoglobin $(\mathrm{Hb})$ of $17.6 \mathrm{~g} / \mathrm{dL}$, mean corpuscular volume of $107 \mathrm{fL}$, total leukocyte count of $17 \times 10^{3} / \mu \mathrm{L}$, platelet count (PLT) of $225 \times 10^{3} / \mu \mathrm{L}$, and C-reactive protein of $0.5 \mathrm{mg} / \mathrm{dL}$. On the third day, acyclovir was started and antibiotics were changed to meropenem and linezolid as the patient showed no improvement. However, the patient's GCS remained low (score <8). Ultrasound (US) brain was normal, and CSF detailed report showed protein of $103.3 \mathrm{mg} / \mathrm{dL}$, glucose 95 $\mathrm{mg} / \mathrm{dL}$, chloride of $115 \mathrm{mmol} / \mathrm{L}$, and lymphocyte count of 4 with no red blood cells and polymorphs. Urine, CSF, and blood cultures showed no bacterial growth.

On the fourth day, the child's GCS was still low and pupils became sluggishly reactive with poor reflexes. Non-improvement in the patient's condition led to the suspicion of a metabolic disorder. Samples were sent to check serum ammonia, arterial blood gases (ABGs), and urinary ketones. On the fifth day, the pupils became mid-dilated and sluggishly reactive to light. Serum ammonia was found to be elevated ( $443 \mu \mathrm{g} / \mathrm{dL}$, $\mathrm{N}<225 \mu \mathrm{g} / \mathrm{dL}$ ). ABGs showed mixed severe respiratory and mild metabolic acidosis with an anion gap of 12 and lactate levels of $2.5 \mathrm{mmol} / \mathrm{L}$. Urine was negative for ketones, and RBS was normal throughout the stay. Laboratory investigations throughout the course of stay are summarized in Table 1.

\begin{tabular}{|c|c|c|c|c|c|c|}
\hline Laboratory Investigation & Normal Value (units) & Day 3 & Day 7 & Day 13 & Day 17 & Day 21 \\
\hline $\mathrm{Hb}$ & $11-15.5$ (g/dL) & 19.1 & 14.5 & 13.5 & 13.6 & 12.2 \\
\hline MCV & $80-100$ (fL) & 98 & 98 & 92.7 & 102 & 106 \\
\hline TLC & $4-11\left(\times 10^{3} / \mu \mathrm{L}\right)$ & 13.6 & 16.3 & 14.5 & 17.8 & 19.4 \\
\hline PLT & $140-400\left(x 10^{3} / \mu \mathrm{L}\right)$ & 187 & 140 & 105 & 14 & 39 \\
\hline CRP & $2-5(\mathrm{mg} / \mathrm{dL})$ & 3.1 & 41.6 & 96.6 & 130 & 155 \\
\hline BUN & 2.5-7.1 (mmol/L) & 10 & 15 & 11 & 4 & 3 \\
\hline $\mathrm{Cr}$ & $0.3-0.7(\mathrm{mg} / \mathrm{dL})$ & 1.1 & 1.2 & 1.0 & 0.4 & 0.3 \\
\hline $\mathrm{Na}$ & 135-145 (mEq/L) & 135 & 142 & 134 & 135 & 140 \\
\hline $\mathrm{K}$ & 3.0-5.0 (mEq/L) & 4.3 & 3.5 & 3.1 & 3.2 & 3.0 \\
\hline $\mathrm{Ca}$ & $8.5-10.5$ (mg/dL) & 7.3 & 8.3 & 7.6 & 8.6 & 8.1 \\
\hline T Bil & $0.3-1.0(\mathrm{mg} / \mathrm{dL})$ & 5.26 & 9.83 & 6.19 & 3.14 & 3.44 \\
\hline PT & 10.5 (seconds) & 13.7 & 14.6 & 18.2 & 16.0 & 15.7 \\
\hline APTT & 26-36 (seconds) & 30.8 & 32.2 & 28.5 & 29.6 & 28.1 \\
\hline INR & $\leq 1.10$ & 1.38 & 1.49 & 1.93 & 1.66 & 1.62 \\
\hline
\end{tabular}

\section{TABLE 1: Laboratory investigations of the patient during the course of hospital stay}

$\mathrm{Hb}$, hemoglobin; MCV, mean corpuscular volume; TLC, total leukocyte count; PLT, platelets; CRP, C reactive protein; BUN, blood urea nitrogen; Cr, creatinine; $\mathrm{Na}$, sodium; K, potassium, Ca, calcium; T Bil, total bilirubin; PT, prothrombin time; APTT, activated partial thromboplastin time; INR, international normalized ratio

Considering the differential of aminoacidopathies, serum amino acid chromatography and urine organic acid chromatography were ordered. For hyperammonemia, the patient was managed on IV sodium benzoate $500 \mathrm{mg}$ loading dose over two hours with a maintenance dose of $500 \mathrm{mg} /$ day infusion over 24 hours. This regimen was continued for four days, and serum ammonia was repeated which decreased to $226 \mu \mathrm{g} / \mathrm{dL}$ and then $80 \mu \mathrm{g} / \mathrm{dL}$ at which sodium benzoate was stopped.

There was a slight improvement in GCS and respiratory rate during treatment. Attempts of spontaneous breathing trials were failed. PLT and Hb levels dropped and fluctuation was noticed in urea creatinine electrolytes for which the patient was managed accordingly. Attempts to start feeding were done, but the patient could not tolerate more than $5 \mathrm{~mL}$ in four hours.

During her stay, the patient developed generalized tonic seizures for which levetiracetam was started. No 


\section{Cureus}

improvement in GCS was observed even after anti-epileptic therapy (AET). Urine organic acid chromatography was unremarkable. However, serum amino acid chromatography showed severely increased levels of glycine documented about $>2,500 \mu \mathrm{mol} / \mathrm{L}$ [ $\mathrm{N}=101-317]$. The detailed report of serum amino acid chromatography is shown in Table 2 .

\begin{tabular}{|c|c|c|}
\hline Amino Acid & Normal Levels (Units) & Results \\
\hline Taurine & $14-238(\mu \mathrm{mol} / \mathrm{L})$ & 242 \\
\hline Aspartate & $1-21(\mu \mathrm{mol} / \mathrm{L})$ & 16 \\
\hline Threonine & $60-141(\mu \mathrm{mol} / \mathrm{L})$ & 129 \\
\hline Serine & $62-206(\mu \mathrm{mol} / \mathrm{L})$ & 202 \\
\hline Asparagine & 38-114 ( $\mu \mathrm{mol} / \mathrm{L})$ & 85 \\
\hline Glutamate & $32-104(\mu \mathrm{mol} / \mathrm{L})$ & 133 \\
\hline Glutamine & 198-886 ( $\mu \mathrm{mol} / \mathrm{L})$ & 379 \\
\hline Glycine & $101-317(\mu \mathrm{mol} / \mathrm{L})$ & $>2500$ \\
\hline Alanine & 108-448 ( $\mu \mathrm{mol} / \mathrm{L})$ & 452 \\
\hline Citrulline & $5-33(\mu \mathrm{mol} / \mathrm{L})$ & 42 \\
\hline Valine & 65-201 ( $\mu \mathrm{mol} / \mathrm{L})$ & 143 \\
\hline Cystine & $20-60(\mu \mathrm{mol} / \mathrm{L})$ & 38 \\
\hline Methionine & 6-50 ( $(\mu \mathrm{mol} / \mathrm{L})$ & 27 \\
\hline Isoleucine & $22-82(\mu \mathrm{mol} / \mathrm{L})$ & 31 \\
\hline Leucine & $47-175(\mu \mathrm{mol} / \mathrm{L})$ & 86 \\
\hline Tyrosine & $38-178(\mu \mathrm{mol} / \mathrm{L})$ & 45 \\
\hline Phenylalanine & $21-85$ ( $\mu \mathrm{mol} / \mathrm{L})$ & 57 \\
\hline Ornithine & $31-207(\mu \mathrm{mol} / \mathrm{L})$ & 103 \\
\hline Lysine & 67-291 ( $\mu \mathrm{mol} / \mathrm{L})$ & 337 \\
\hline Histidine & $25-113(\mu \mathrm{mol} / \mathrm{L})$ & 66 \\
\hline Arginine & $12-116(\mu \mathrm{mol} / \mathrm{L})$ & 46 \\
\hline Proline & $20-344(\mu \mathrm{mol} / \mathrm{l}$ & 187 \\
\hline
\end{tabular}

\section{TABLE 2: Detailed report of serum amino acid chromatography}

Sodium benzoate was started to reduce serum glycine levels. The patient was diagnosed as a classic neonatal type of NKH which has a very poor prognosis. For further confirmation of diagnosis, CSF glycine levels could not be done due to financial constraints. Another therapeutic option, dextromethorphan (N-methyl-Daspartate [NMDA] receptor antagonist), was started at $4 \mathrm{mg}$ eight hourly. Unfortunately, the child did not respond to this treatment.

Around the 18th day of admission, the pupils became fixed, dilated, and non-reactive to light. She could not be weaned off from the ventilator. The disease and prognosis of the patient was explained to parents. After a discussion with parents, a do-not-resuscitate code was decided and supportive management was continued. Unfortunately, the patient expired on the 22nd day of admission.

\section{Discussion}

$\mathrm{NKH}$, also known as glycine encephalopathy, is a rare lethal AR metabolic disorder caused by the defect in glycine cleavage enzyme (GCE). Although NKH is uncommon worldwide, it is relatively more common in Finland where it occurs in one in 55,000 newborns [7]. The neonatal type of NKH has a more severe prognosis than late-onset type, and it is characterized by rapid development of neurological symptoms like 
lethargy, hypotonia, apnea, and seizures. These effects occur due to the accumulation of glycine in different parts of the brain that have glycine receptors. Glycine receptors in the cerebrum and cerebellum have stimulating effects, and accumulation of glycine in these areas leads to the development of seizures, myoclonus, and encephalopathy [8]. Our patient presented with similar complaints of lethargy and reluctance to feed. Clinical examination revealed muscular hypotonia with hyporeflexia and poorly reactive pupils. Later she developed apnea, bradycardia, and generalized tonic seizures not responding to AET.

NKH is primarily diagnosed by determining the glycine levels in plasma and urine. In case of high glycine levels and the absence of ketonemia, the CSF glycine and ratio of CSF glycine to plasma are measured [9]. The definitive diagnosis of NKH is made by measuring the level of GCE on liver biopsy. GCE is a mitochondrial enzyme comprising four different proteins (glycine decarboxylase; P-protein, hydrogen carrier protein; H-protein, aminomethyltransferase; T-protein, and dihydrolipoamide dehydrogenase; Lprotein). Any kind of mutation in genes encoding these proteins can lead to NKH [10]. Serum amino acid chromatography revealed an approximately 10 -fold increase in glycine levels in our patient. However, CSF glycine and GCE levels were not determined due to a lack of financial support. Similarly, no significant findings were observed in the US brain of our patient which coincides with the fact that imaging studies are not so effective in diagnosing this condition. Considering that the signs and symptoms of this disorder mimic sepsis, encephalitis, or meningitis, the patient was advised for CSF detailed report, blood, urine, and CSF culture. However, no significant bacterial growth was observed in these reports.

Being a fatal disease, NKH has devastating consequences. The majority of patients die within the first week of life and those who survive suffer from severe mental retardation [11]. Seizures in this disorder do not respond to conventional AET, and the patient ultimately dies. It has also been observed that the brain is less affected by the toxic concentration of glycine and develop lesser complications if the condition is diagnosed and managed earlier [12]. In a resource-limited setup, such types of rare conditions are difficult to diagnose and treat which consequently leads to the death of affected patients and a decline in overall prognosis.

The treatment of NKH consists of three drug groups. (1) Plasma glycine-lowering agents like benzoate that reduce the level of plasma and CSF glycine leading to a decrease in seizure frequency. These drugs improve arousal but have no impact on the neurological status of the individual [12-14]. (2) NMDA inhibitors are another group of drugs that control seizures and improve neurological functions by antagonizing the effects of NMDA receptors in the brain. Two important drugs of this group are dextromethorphan, a common antitussive, and ketamine. These drugs particularly improve neonatal swallowing and sucking reflexes and modify abnormal electroencephalographic discharges from the brain $[13,15,16]$. (3) Competitive glycine inhibitors which include strychnine. These drugs are used to treat mild cases of NKH [16].

Due to the lack of definitive diagnosis at admission, our patient was initially given symptomatic treatment but no improvement by antibiotics and antiviral agents was observed. IV sodium benzoate was administered considering increased levels of serum ammonia and an improvement in GCS was observed for a short period of time. Later the deterioration of condition due to the development of seizures created a diagnostic dilemma. Medication (levetiracetam) was not able to control seizures in this patient. After confirmation of the diagnosis and thorough literature search, the patient was started on sodium benzoate and dextromethorphan. However, a transient neurological improvement was observed after the initiation of treatment with glycine-lowering drugs. Parents were counseled about the poor prognosis of this condition.

Due to delay in diagnosis and appropriate treatment, there was a high possibility that the CNS of this patient probably had been irreversibly damaged by the toxic accumulation of glycine. Therefore, it is imperative to make a correct diagnosis as early as possible to improve mortality in these patients. This can further aid in genetic counseling and appropriate prenatal diagnosis in subsequent pregnancies. Unfortunately, the patient did not survive due to a lack of prompt management in a resource-limited setting.

\section{Conclusions}

Since most of the clinical features of inborn errors of metabolism coincide with sepsis or other common diseases of the neonatal period, a delay is observed in diagnosis and adequate management of rare cases like $\mathrm{NKH}$. This leads to devastating outcomes as highlighted in our study. It cannot be emphasized enough that early diagnosis and care of neonatal NKH is crucial. In our case, due to lack of prompt investigations and diagnosis, the delay in initiation of treatment led to a steep decline in patient's condition. Despite the putative treatment with sodium benzoate and dextromethorphan, the prognosis of this condition is still grave. Hence, it is important to consider NKH among differential diagnoses of a neonate coming with seizures and altered level of consciousness without distinct acid-base disturbances.

\section{Additional Information \\ Disclosures}

Human subjects: All authors have confirmed that this study did not involve human participants or tissue. Conflicts of interest: In compliance with the ICMJE uniform disclosure form, all authors declare the following: Payment/services info: All authors have declared that no financial support was received from 
any organization for the submitted work. Financial relationships: All authors have declared that they have no financial relationships at present or within the previous three years with any organizations that might have an interest in the submitted work. Other relationships: All authors have declared that there are no other relationships or activities that could appear to have influenced the submitted work.

\section{References}

1. Hennermann JB: Clinical variability in glycine encephalopathy. Future Neurol. 2006, 1:621-630. 10.2217/14796708.1.5.621

2. Tada K, Kure S: Nonketotic hyperglycinemia: pathophysiological studies. Proc Jpn Acad Ser B Phys Biol Sci. 2005, 81:411-417. 10.2183/pjab.81.411

3. Hoover-Fong JE, Shah S, Van Hove JL, Applegarth D, Toone J, Hamosh A: Natural history of nonketotic hyperglycinemia in 65 patients. Neurology. 2004, 63:1847-1853. 10.1212/01.WNL.0000144270.83080.29

4. Dobyns WB: Agenesis of the corpus callosum and gyral malformations are frequent manifestations of nonketotic hyperglycinemia. Neurology. 1989, 39:817-820. 10.1212/WNL.39.6.817

5. Mohammad SA, Abdelkhalek HS: Nonketotic hyperglycinemia: spectrum of imaging findings with emphasis on diffusion-weighted imaging. Neuroradiology. 2017, 59:1155-1163. 10.1007/s00234-017-1913-0

6. Volpe JJ: Hyperammonemia and other disorders of amino acid metabolism . Neurology of the Newborn. Volpe JJ (ed): WB Saunders, Philadelphia; 2008. 1:659-667.

7. Von Wendt L, Similä S: Experience with non-ketotic hyperglycinaemia in Finland. J Inherit Metab Dis. 1982, 5:111-112. 10.1007/BF01805574

8. Poothrikovil RP, Al Thihli K, Al Futaisi A, Al Murshidi F: Nonketotic hyperglycinemia: two case reports and review. Neurodiagn J. 2019, 59:142-151. 10.1080/21646821.2019.1645549

9. Korman SH, Gutman A: Pitfalls in the diagnosis of glycine encephalopathy (non-ketotic hyperglycinemia) . Dev Med Child Neurol. 2002, 44:712-720. 10.1111/j.1469-8749.2002.tb00275.x

10. Coughlin CR, Swanson MA, Kronquist K, et al.: The genetic basis of classic nonketotic hyperglycinemia due to mutations in GLDC and AMT. Genet Med. 2017, 19:104-111. 10.1038/gim.2016.74

11. Tada K: Nonketotic hyperglycinemia. Inborn Metabolic Diseases. Fernandes J, Saudubray JM, Van den Berghe G (ed): Springer, Berlin, Heidelberg; 2000. 1:254-258. 10.1007/978-3-662-04285-4_21

12. Hui HNT, Ho YC, Chan HB, Tam SCF, Tang NLS, Ip PLS: A baby with nonketotic hyperglycinaemia . HK J Paediatr. 2004, 9:243-247.

13. Hamosh A, Maher JF, Bellus GA, Rasmussen SA, Johnston MV: Long-term use of high-dose benzoate and dextromethorphan for the treatment of nonketotic hyperglycinemia. J Pediatr. 1998, 132:709-713. 10.1016/s0022-3476(98)70365-8

14. Neuberger JM, Schweitzer S, Rolland MO, Burghard R: Effect of sodium benzoate in the treatment of atypical nonketotic hyperglycinaemia. J Inherit Metab Dis. 2000, 23:22-26. 10.1023/a:1005642728513

15. Ohya Y, Ochi N, Mizutani N, Hayakawa C, Watanabe K: Nonketotic hyperglycinemia: treatment with NMDA antagonist and consideration of neuropathogenesis. Pediatr Neurol. 1991, 7:65-68. 10.1016/08878994(91)90110-7

16. Tegtmeyer-Metzdorf H, Roth B, Günther M, et al.: Ketamine and strychnine treatment of an infant with nonketotic hyperglycinaemia. Eur J Pediatr. 1995, 154:649-653. 10.1007/bf02079070 